Mycologia, 101(6), 2009, pp. 871-877. DOI: 10.3852/08-121

(C) 2009 by The Mycological Society of America, Lawrence, KS 66044-8897

\title{
Kumanasamuha geaster sp. nov., an anamorph of Chorioactis geaster from Japan
}

\author{
H. Nagao ${ }^{1,2}$ \\ Genebank, National Institute of Agrobiological Sciences, \\ Tsukuba 305-8602, Japan
S. Kurogi
Miyazaki Prefectural Museum of Nature and History, Miyazaki 880-0053, Japan
E. Kiyota
Kyusyu University of Health and Welfare, Nobeoka 882-8508, Japan

K. Sasatomi

Kyusyu Environmental Evaluation Association, Fukuoka 813-0004, Japan

\begin{abstract}
A new species of Kumanasamuha is described and illustrated from axenic single-spore isolates of Chorioactis geaster. The characteristics of conidia and hyphae are the same as the dematiaceous hyphomycete observed on decayed trunks of Quercus spp., where C. geaster appeared in the field in Japan. Our results indicated that C. geaster in situ colonizes decayed trunks of Quercus spp.

Key words: axenic culture, Chorioactidaceae, conidiogenous cell, discomycetes, polyblastic sporulation, Sarcosomataceae
\end{abstract}

\section{INTRODUCTION}

Chorioactis geaster (Peck) Kupfer ex Eckblad (syn. Urnula geaster Peck) is known to exist only in Japan and USA. The distribution areas are $\sim 11000 \mathrm{~km}$ distant and localized only in certain places, namely Miyazaki in Japan and Texas in USA. The taxonomic history of $C$. geaster was reviewed by Peterson et al (2004). Harrington et al (1997) first defined the restricted families Sarcoscyphaceae and Sarcosomataceae and noted that $C$. geaster formed a distinct lineage but with less than $50 \%$ bootstrap support. This distinct lineage, referred to as the Chorioactis clade, was highly supported by SSU and LSU rDNA sequences (Hansen and Pfister 2006). Perry et al (2007) showed a group of taxa centered on C. geaster, in agreement with results of Harrington et al (1997) and Peterson et al (2004). The Chorioactis clade was explored further with RPB2, LSU and SSU rDNA

\footnotetext{
Accepted for publication 12 May 2009.

${ }^{1}$ Corresponding author. E-mail: nagaoh@usm.my

${ }^{2}$ Current address: School of Biological Sciences, Universiti Sains Malaysia, 11800 Pulau Pinang, Malaysia
}

sequences and morphology. The combination of the three datasets produced similar or stronger support for this lineage. A new family, Chorioactidaceae, was erected in the Pezizales (Pfister et al 2008) to accommodate Chorioactis and three other genera, Desmazierella, Neournula and Wolfina.

Chorioactis geaster has been found in evergreen broadleaf forests in Kyusyu, Japan (Imazeki 1938, Imazeki and Otani 1975, Kurogi et al 2002). However these forests are now disappearing due to deforestation and replanting with Cryptomeria japonica D. Don and construction of a dam. Chorioactis geaster has been listed as a threatened fungus in the Red Data Book of Japan (2000) because of its global rarity. The occurrence of C. geaster was infrequent (Imazeki 1938, Imazeki and Otani 1975) and asexual sporulation of C. geaster was not observed (Imazeki and Otani 1975). We have made some observations on the life cycle of $C$. geaster and are trying to find ways to conserve this endangered fungus (Kurogi et al 2002).

One of us (EK) observed a black-brown tufted structure coverings on decayed trunks usually associated with the appearance of $C$. geaster fruit bodies. Peterson et al (2004) also described this black-brown tufted structure as Conoplea aff. elegantula. They estimated the time of divergence between American and Japanese lineages of C. geaster with LSU and SSU rDNA sequences. They also demonstrated the phylogenetic connection between Japanese Chorioactis and its Conoplea anamorph with the internal transcribed spacer (ITS) region of nrDNA. Chorioactis geaster of the American collections did not germinate on artificial media and no anamorph connection was established for the American material (Peterson et al 2004). In this study we report the anamorph in axenic cultures from single-spore isolates of $C$. geaster. We also present observations on anamorph formation in situ.

\section{MATERIALS AND METHODS}

Isolate.-Single-spore isolates of C. geaster were obtained from three fruiting bodies collected in Kobayashi-shi, Miyazaki Prefecture, Japan. Each germling grew well on acidified potato dextrose agar (PDA, Difco) but no conidia were formed on this medium, as reported by Imazeki and Otani (1975).

Anamorph formation.-Fresh leaves of Quercus gilva Blume, Q. glauca Blume, Q. salicina Blume, Q. myrsinifolia Blume, Q. sessilifolia Blume and Distylium racemosum Sieb. et Zucc. were collected from fields in Miyazaki Prefecture, Japan, 

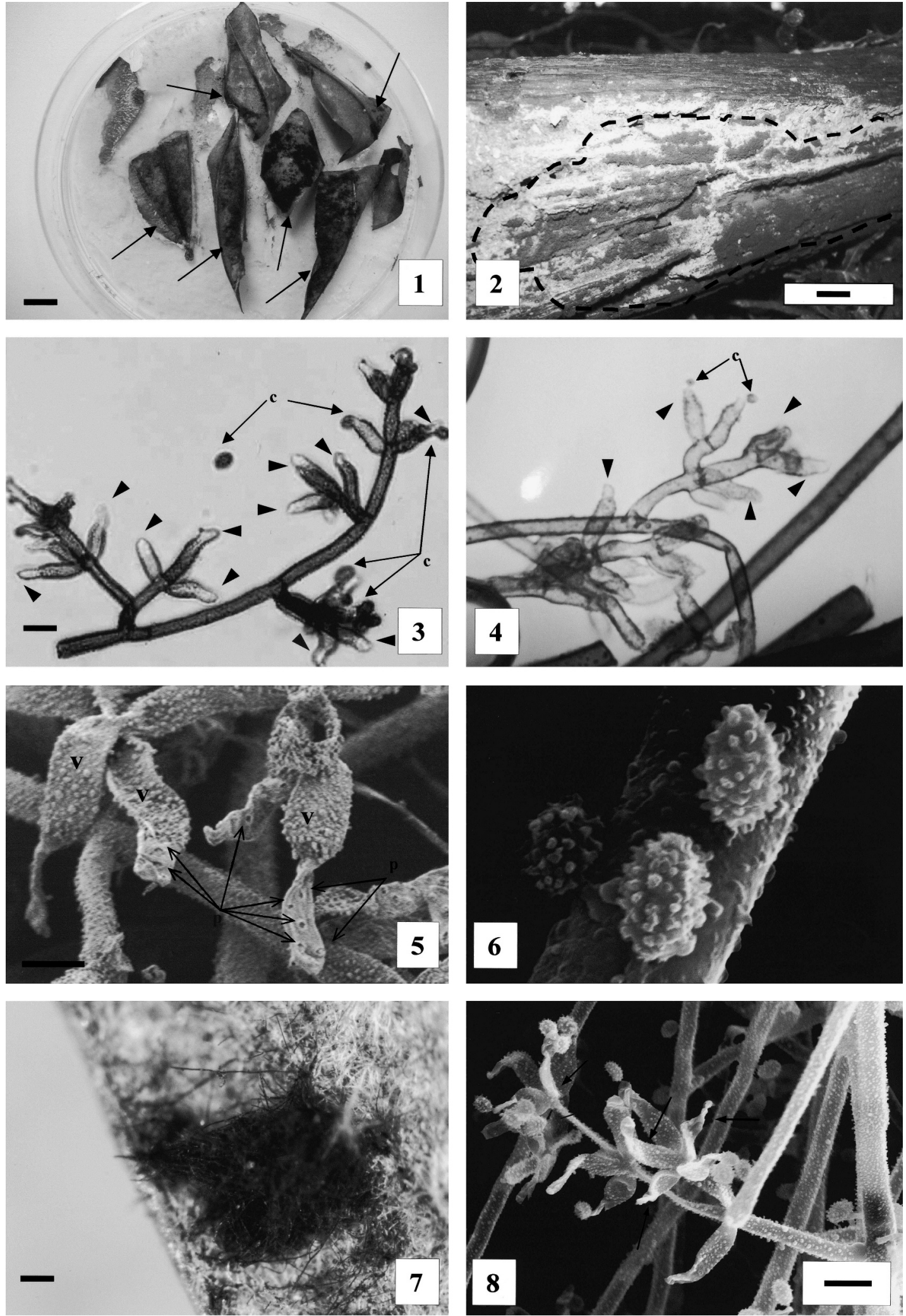

Figs. 1-8. 1. Black-brown tufted growth appeared on the sterilized leaves of Quercus sessilifolia in vitro. Bar: $1 \mathrm{~cm} .2$. Blackbrown tufted growth on the decayed trunks in Miyazaki Prefecture, Japan (Circled with white doted line). Bars: 2 cm. 3. Conidiophore (arrowhead) and conidia (c) induced in the black-brown tufted growth on sterilized leaves of Quercus sessilifolia in vitro. Bar: $10 \mu \mathrm{m}$. 4. Conidiophore (arrow) and conidia (c) induced in the black-brown tufted growth on decayed trunks in 
TABLE I. Anamorph induction in vitro on the sterilized leaves of Quercus spp. and Distylium racemosum

\begin{tabular}{|c|c|c|c|c|c|c|c|}
\hline \multirow[b]{2}{*}{ Species of inoculated leaf } & \multicolumn{2}{|c|}{ NBRC100691 } & \multirow[b]{2}{*}{ MAFF240013 } & \multicolumn{2}{|c|}{ NBRC100692 } & \multicolumn{2}{|c|}{ Cont. } \\
\hline & $1 \mathrm{st}$ & 2nd & & $1 \mathrm{st}$ & 2nd & $1 \mathrm{st}$ & 2nd \\
\hline Quercus gilva & + & - & - & + & - & - & - \\
\hline$\widetilde{Q} \cdot$ glauca & - & - & + & + & + & - & - \\
\hline Q. salicina & + & + & - & + & - & - & - \\
\hline Q. myrsinifolia & - & $\mathrm{NT}^{1}$ & NT & - & NT & - & - \\
\hline Q. sessilifolia & + & - & - & + & - & - & - \\
\hline Distylium racemosum ${ }^{2}$ & - & NT & NT & - & NT & - & - \\
\hline
\end{tabular}

${ }^{1}$ Not tested.

${ }^{2}$ Spore mass were produced after $1 \mathrm{y}$ incubation.

stored in plastic bags and refrigerated. The leaves were sterilized by autoclaving as soon as they arrived in the laboratory, then aseptically placed on modified WeitzmanSilva-Hunter agar (WSH: $\mathrm{MgSO}_{4} \cdot 7 \mathrm{H}_{2} \mathrm{O} 1 \mathrm{~g}, \mathrm{KH}_{2} \mathrm{PO}_{4} 1 \mathrm{~g}$, $\mathrm{NaNO}_{3} 1 \mathrm{~g}$, Quaker oatmeal $10 \mathrm{~g}$, agar $20 \mathrm{~g}$, water $1000 \mathrm{~mL}$ ) in $90 \mathrm{~mm}$ diam Petri dishes. Each dish was employed for further experiments after checking the sterility of the medium. A piece of PDA block with $C$. geaster culture was transferred to each dish. Inoculated dishes were sealed with Parafilm ${ }^{\circledR}$ and incubated in the room near a window. Room temperature was about $25 \mathrm{C}$. This test was repeated twice.

Observations of conidia and hyphae.-Colony growth was observed periodically without magnification to detect conidium formation. When the colony turned black-brown it was examined by light microscope and scanning electron microscope (SEM). For observation by SEM the samples were air-dried, fastened with carbon double-sided tape (Nisshin EM Co. Ltd., Tokyo) on an aluminum stub (15 mm diam $\times 7 \mathrm{~mm}$ ) (Nisshin EM Co. Ltd., Tokyo) and coated with about $4 \mathrm{~nm}$ palladium. The samples were examined in a VE-7800 scanning electron microscope (Keyence Co. Ltd., Osaka).

Anamorph surveys in the field.-We conducted two field surveys to detect the anamorph of C. geaster. In the first survey fallen leaves (e.g. those of $Q$. gilva, Q. glauca and Acer palnatum Thunb.) were collected on the ground in the forest 5 Oct 2005, Kobayashi-shi, Miyazaki Prefecture, Japan. Species composition of the forest was described in Kurogi at al (2002). This material was examined under a dissecting microscope to detect colonies of C. geaster. Material with the anamorph was examined further under a light microscope and by SEM as described above.

In a second experiment we tried to isolate $C$. geaster from living tissues of the Quercus species listed above (excluding
D. racemosum). Five pieces of leaves of each species were surface-sterilized by successively dipping in $70 \%$ ethanol for $1 \mathrm{~min}, 5 \% \mathrm{NaClO}$ for $5 \mathrm{~min}$ and sterilized distilled water for 3 min 3 times. Leaves were blotted dry and placed on acidified water agar in $90 \mathrm{~mm}$ diam Petri dishes. In addition 55 cuttings $(30 \mathrm{~mm}$ long $\times 3-6 \mathrm{~mm}$ diam) of branches from $Q$. salicina were treated in a similar way. Inoculated Petri dishes were incubated in the dark at 22 C. Growing colonies were observed and transferred onto acidified PDA. These isolates again were inoculated on WSH with sterilized leaves of $Q$. gilva, $Q$. glauca and $Q$. salicina.

\section{RESULTS}

Anamorph induction in vitro.-Conidium formation was observed on the leaves of $Q$. gilva, $Q$. glauca, $Q$. salicina and Q. sessilifolia (TABLE I). However reproducibility of conidium formation fluctuated between the first and second tests. In the first test the isolate preserved as NBRC 100691 grew out well and formed conidia on all plant species except $Q$. glauca and $Q$. myrsinifolia. NBRC 100691 also colonized and formed conidia on $D$. racemosum after $1 \mathrm{y}$. A second isolate, NBRC 100692, colonized only Q. glauca. The colonies densely covered the surface of inoculated leaves (FIG. 1), resembling the black-brown mossy covering on decayed trunks seen in the field (FIG. 2). In a second test isolate NBRC 100691 colonized only $Q$. salicina but isolates MAFF 240013 and NBRC 100692 colonized only Q. glauca. NBRC 100691 initially colonized the petiole then spread over the leaf surface of Q. salicina. Isolate MAFF 240013 colonized the petiole of $Q$. glauca. Average colony diameter was $54.2 \mathrm{~mm}$ after $1 \mathrm{wk}$.

Miyazaki Prefecture, Japan. Bar: $10 \mu \mathrm{m}$. 5. Ampliform or lageniform conidiogenous cells of Kumanasamuha geaster covering with verruculate particles (v). Traces of polyblastic conidial formation ( $p$ ) observed on the tip of conidiogenous cells. Bar: $10 \mu \mathrm{m}$. 6. Oval to ellipsoidal conidia of Kumanasamuha geaster. Bar: $2.5 \mu \mathrm{m}$. 7. Black-brown tufted colony on fallen leaf collected in Miyazaki Prefecture, Japan. Bar: $500 \mu \mathrm{m}$. 8. Conidiophore (arrow) observed in the black-brown tufted colony on fallen leaf collected in Miyazaki Prefecture, Japan. Bar: $10 \mu \mathrm{m}$. 
Morphology of hyphae and conidia.-Hyphae were brown but transparent, thick-walled, finely verruculose, septate and straight (FIG. 3), such as those seen in black-brown tufted growth on decayed trunks in the field (FIG. 4). Conidiophores arising from creeping hyphae were brown and verrucose, bearing 1-3 clusters/whorls of branches in the upper part, each with 1-3 short, cylindrical conidiogenous cells (FIG. 5). Conidia formed singly in a sympodial succession on hollow scars, circa $0.7 \mu \mathrm{m}$; conidia dark brown, oval to ellipsoidal, verrucose. Conidia were easily liberated from the hyphal mass (FIG. 6). Conidia did not germinate on water agar.

Anamorph surveys in the field.-In the first field survey $5000 \mathrm{~mL}$ (81.2 $\mathrm{g}$ dry weight) fallen leaves was sampled. A total of 736 leaf fragments were collected, of which 281 were evergreen and the others (455) were deciduous broadleaves; twig pieces less than $10 \mathrm{~cm}$ long also were collected. The characteristic anamorph of C. geaster appeared on four evergreen leaves, that is Machilus japonica Kosterm.(BDCJ FUN32), Q. glauca (BDCJ FUN34) and Q. hondae Makino (BDCJ FUN33 and 35). These colonies were less than $1 \mathrm{~mm}$ diam (FIG. 7), but numerous conidia were formed (FIG. 8).

In the second experiment Pestalotiopsis spp., Phomopsis sp. and Seimatosporium sp. were recovered frequently from surface-sterilized host foliage but the anamorph of $C$. geaster was absent. Six nonsporulating brown fungi isolated from living leaves were inoculated on sterilized leaves of Quercus spp. on WSH but did not form the characteristic colonies and conidia of C. geaster. Control inoculations of sterilized leaves on WSH with C. geaster cultures produced the characteristic black-brown tufted structures, hyphae, conidiophores and conidia similar to those formed on decayed trunks. The morphology of this fungus was equated to that of genus Kumanasamuha. None of the four species described in this genus matched our fungus. Therefore we propose this fungus as a new species.

\section{TAXONOMY}

Kumanasamuha geaster H. Nagao, S. Kurogi et E. Kiyota, sp. nov. FIG. 9 MycoBank MB 510857

Coloniae brunneae, floccosae vel lanuginosae. Hyphae aeriae steriles, simplices vel ramosae, 4-9 $\mu \mathrm{m}$ latae, apicem versus attenuatae, pariete uniformiter et conspicue verrucoso, atrobrunnei, ad intervalla, irregularia septatae. Conidiophora macronematosa, mononematosa, ramose, pariete uniformiter et conspicue verrucosa in parte superiore identidem plus minusve verticillatim ramosa. Cellulae conidiogenae plus minusve verticillatae, e ventre sterili, ampulliformi vel lageniformi, verruculoso, crassitunicato, fusco-brunneo et rachide, subglobosa, fertili, pallide brunnea, exigue recavae cicatices constantes. Conidia solitaria, sicca, ovalia vel ellipsoidea, fusco-brunnea, verruculosa, aseptata, (5-) 6-7 × (3-) 3.5-4.5(-5) $\mu \mathrm{m}$.

Holotypus: BDCJ FUN43, colonia siccata ex cultura a H. Nagao isolate ex cortice putrido Quercus sessilifoliae Thumb., Kobayashi, Miyazaki Pref. in Japonia, 13 Feb 2003, in herbario Biodiversity Center, nature Conservation Bureau, ministry of the Environment, Yamanashi, Japonia conservatus.

Living cultures: CBS 121399 and 121400, MAFF 240013, NBRC 100691 and 100692 (ex-type). An ascospore isolate from a fruiting body.

Colonies on the natural substrate brown, floccose or wooly, composed of intermingled conidiophores and sterile hyphae. Aerial sterile hyphae simple or branched, superficial, tapering toward the apex, walls uniform, conspicuously verrucose, dark brown, septate at irregular intervals. Conidiophores erect, macronematous, mononematous, more or less verticillately branched in the upper part; walls uniformly, conspicuously verrucose. Conidiogenous cells discrete, formed in groups of 2-15 sterile, ampliform to lageniform, thick-walled, dark brown venter and a narrower, subglobose, pale brown, thin-walled, apically hollow scared rachis. Conidia solitary, dry, oval to ellipsoidal, dark brown, verrucose, nonseptate, (5-)6$7 \times(3-) 3.5-4.5(-5) \mu \mathrm{m}$.

This species seems to belong to Kumanasamuha $\mathrm{P}$. Rag. Rao \& D. Rao (1964) as also described by Ellis (1971). Four species have been described: $K$. sundara P. Rag. Rao \& D. Rao (1964), K. novazealandica I. L. Hunter \& W. B. Kendrick (1977), K. arakuensis T. Raman, Ren. Rao \& D. Rao (1978) and K. kalakadensis Subram. \& Bhat (1989). Our fungus is strikingly different in the shape of the conidiogenous cells, which are ampulliform or lageniform (FIGS. 5, 9), whereas they are flask-shaped, spherical to subspherical in the four previously described species; they also consist of two parts, a verrucose brown venter and a pale brown distal rachis that resembles $K$. kalakadensis. Both species have similar scars of polyblastic sporulation (FIGS. 5, 9). The conidia are not spherical as is the case in $K$. kalakadensis (FIGS. 6, 9).

The four previously described species have been reported to grow on rotten wood ( $K$. sundara), dead stems ( $K$. arakuensis and $K$. nova-zealandica) and deadwood ( $K$. kalakadensis).

\section{DISCUSSION}

Imazeki and Otani (1975) obtained cultures from ascospores of C. geaster. However the mycelia failed to form conidia. We preliminarily examined the conidial 


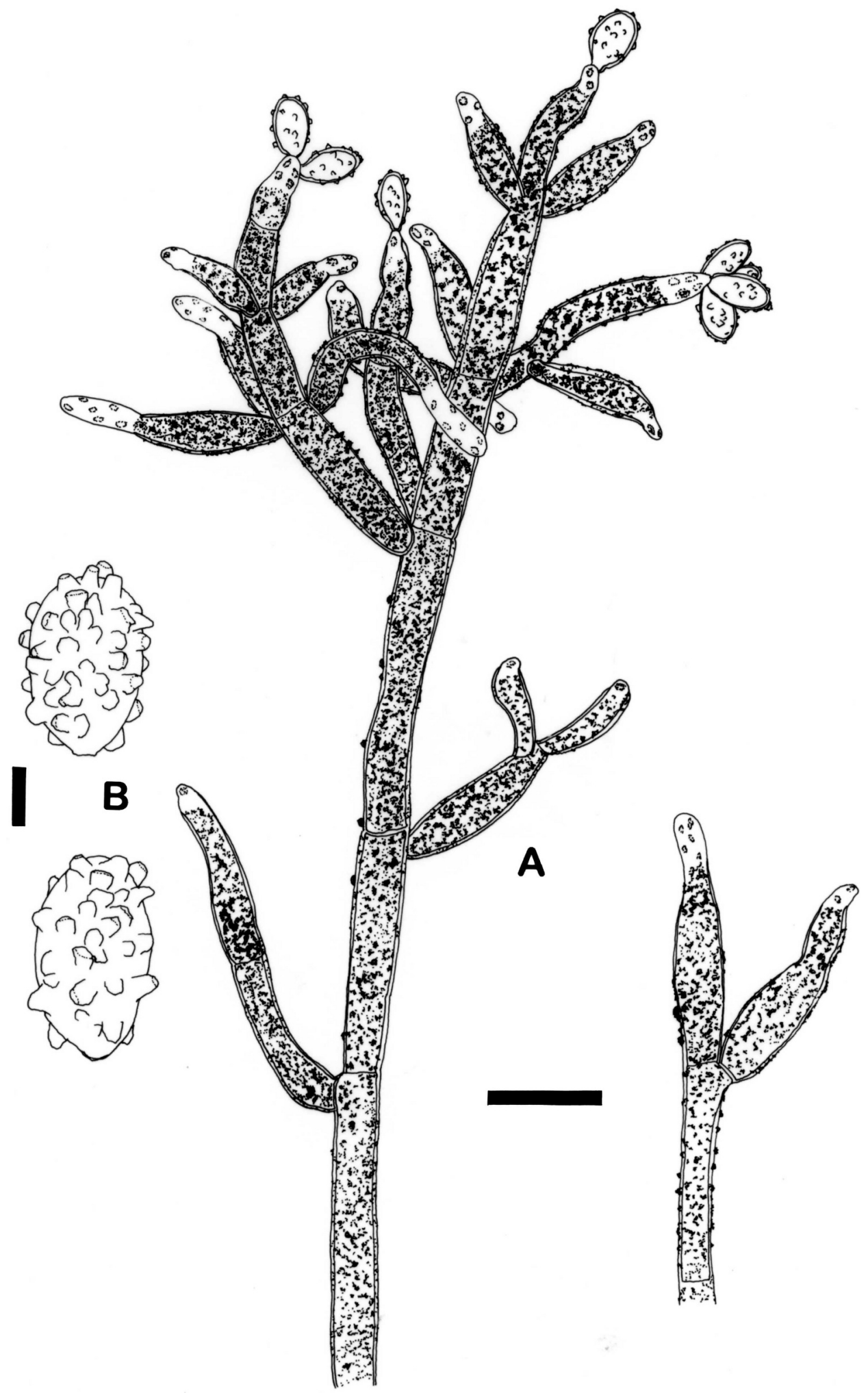

FIG. 9. Conidiophore (A) and conidia (B) induced in the black-brown tufted coverings on sterilized leaves of Quercus sessilifolia in vitro. Bars: $\mathrm{A}=1 \mu \mathrm{m}, \mathrm{B}=2 \mu \mathrm{m}$. 
formation of our ascospore isolates by using different media with and/or without black light. Conidia did not form on artificial media. The anamorph of $C$. geaster, $K$. geaster, however could be induced on sterilized leaves and petioles on WSH agar. Characteristics of mycelia and conidia of $K$. geaster in axenic culture coincide with those seen on decayed trunks in the field. Thus our study has proven the teleomorphanamorph connection. The anamorph of our fungus was identified as Conoplea aff. elegantula (Peterson et al 2004). Branches of conidiophores of Conoplea are somewhat twisted and bear flat conidiation scars (Ellis 1971), while $K$. geaster has straight, verrucose, branched conidiophores (FIGS. 2, 4, 5).

Conoplea species have been directly or indirectly connected to Korfiella karnika DC Pant and VC Tewari, Plectania campylospora (Berk.) Nannf., Plectania nannfeldtii Korf, Sarcosoma latahense Paden and Tylutki and Urmula craterium (Schwein.) Fr. (Peterson et al 2004). With the exception of Korfiella these genera of the Sarcosomataceae are grouped in one major clade in the phylogenetic tree (Harrington et al 1999). On the other hand the clade of Chorioactis, Wolfinia and Neournula (Sarcosomataceae in Korf 1970, 1972; Eriksson 2006), and Desmazierella (Sarcoscyphaceae in Korf 1970, 1972; Eriksson 2006) was identified as an independent clade (Harrington et al 1999) and referred to as the Chorioactis clade with high bootstrap support (Hansen and Pfister 2006). Chorioactis and related genera probably deserve a separate family in a sister relationship with Sarcosomataceae (Hansen and Pfister 2006, Perry et al 2007). The Chorioactis clade and Sarcosomataceae form a strongly supported monophyletic group, using RPB2, LSU and SSU rDNA sequences and morphology, and this clade was erected as a new family, Chorioactidaceae (Pfister et al 2008). Therefore it is preferable to classify this anamorph in Kumanosamuha instead of in Conoplea given their divergent phylogenetic placements. Recognizing family Chorioactidaceae further supports this view.

Kurogi et al (2002) observed fruiting bodies of $C$. geaster on a newly fallen trunk of $Q$. sessilifolia. So we wonder whether discharged ascospores can germinate and colonize decayed wood. In our field survey we found $K$. geaster only on fallen evergreen leaves (FIG. 7). This suggests that ascospores might germinate preferentially on certain fallen leaves. However isolation of C. geaster from living material of $Q$. gilva, $Q$. glauca, $Q$. salicina, $Q$. myrsinifolia and $Q$. sessilifolia was not successful. We suppose that the colonization of fallen leaves resulted from saprobic growth because the colonies were tiny compared to black-brown tufted structure on the decayed trunks in situ and those resulting from our inoculation tests.
We speculate that discharged ascospores of $C$. geaster might reach a living Quercus tree and survive there as an endophyte. Hypoxylon fragiforme also lives within woody tissues and forms extensive mycelium, but it damages or causes stress to the tree when water is lost from the wood (Chapela et al 1990). Because of efforts to isolate C. geaster from living leaves and twigs of Quercus spp. were not successful the fate of discharged ascospores is still unknown.

Conidia did not germinate on water agar, and the conditions for their germination are unknown. However black-brown tufted mycelial growth was obvious from early summer and conidiation occurred June through November in our survey. Primordia of C. geaster were observed in April (Kurogi et al 2002). It is likely that conidia of $K$. geaster also play an important role in distribution and possibly trigger sexual reproduction as a kind of spermatia.

\section{ACKNOWLEDGMENTS}

We thank Prof Baharuddin Salleh, Dr Walter Gams, Prof Ken Katumoto and two anonymous reviewers for reading the manuscript, improving the English and for valuable suggestions.

\section{LITERATURE CITED}

Anonymous. 2000. Threatened wildlife of Japan. In: Environmental Agency of Japan, ed. Bryophytes, algae, lichens, fungi. Red Data Book. 2nd ed. Vol. 9. Tokyo: Japan Wildlife Research Center. 348 p.

Chapela IH, Petrini O, Petrini LE. 1990. Unusual ascospore germination in Hypoxylon fragiforme: first steps in the establishment of an endophytic symbiosis. Can J Bot 68: 2571-2575.

Ellis MB. 1971. Dematiaceous Hyphomycetes. Kew, UK: CMI. 608 p.

Hansen K, Pfister DH. 2006. Systematics of Pezizomycetesthe operculate discomycetes. Mycologia 98:1029-1040.

Harrington FA, Pfister DH, Potter D, Donoghue MJ. 1999. Phylogenetic studies within the Pezizales I. 18SrRNA sequence data and classification. Mycologia 91:41-50.

Hunter LJ, Kendrick WB. 1977. Kumanasamuha novazealandica, a new dematiaceous hyphomycete from New Zealand. N Z J Bot 15:585-588.

Imazeki R. 1938. A rare fungus, Urnula geaster Peck, grows in Kyusyu, Japan. J Jap Bot 14:680-684.

, Otani Y. 1975. Rediscovery of Chorioactis geaster (Peck) Eckblad in Kyusyu, Japan. Trans Mycol Soc Japan 16:222-229.

Kurogi S, Nagao H, Kiyota E. 2002. Investigation of the evolution conditions and environment of endangered fungi Chorioactis geaster. Bull Miyazaki Prefectural Mus Nat Hist 23:23-45.

Perry BA, Hansen K, Pfister DH. 2007. A phylogenetic overview of the family Pyrenomataceae (Ascomycota, Pezizales). Mycol Res 111:549-571. 
Peterson KR, Bell CD, Kurogi S, Pfister DH. 2004. Phylogeny and biogeography of Chorioactis geaster (Pezizales, Ascomycota) inferred from nuclear ribosomal and sequences. Harvard Pap Bot 8:141-152.

Pfister DH, Kurogi S. 2004. A note on some morphological features of Chorioactis geaster (Pezizales, Ascomycota). Mycotaxon 89:277-281.

- Slater C, Hansen K. 2008. Chorioactidaceae: a new family in the Pezizales (Ascomycota) with four genera. Mycol Res 112:513-527.

Raman T, Rao BR, Rao D. 1978. A new species of Kumanasamuha. Curr Sci 47:470-471.

Rao PR, Rao D. 1964. Kumanasamuha a new genus of Dematiaceae. Mycopathol Mycol Appl. 22:330-334.

Subramanian CV, Bhat DJ. 1989 [1987]. Hyphomycetes from South India I. Some new taxa. Kavaka, 15:41-74. 